\title{
Training and Capacity Building: An Essential Strategy for Development at an International Research Center
}

\author{
John Ryan ${ }^{1}$, Habib Ibrahim ${ }^{1}$, Afif Dakermanji ${ }^{1} \&$ Abdoul Aziz Niane ${ }^{1}$ \\ ${ }^{1}$ International Center for Agricultural Research in the Dry Areas (ICARDA), Aleppo, Syria \\ Correspondence: John Ryan, International Center for Agricultural Research in the Dry Areas (ICARDA), Aleppo, \\ Syria. Tel: 963-212-691-2741. E-mail: j.ryan@cgiar.org
}

Received: December 15, 2011 Accepted: January 12, 2012 Online Published: July 5, 2012

doi:10.5539/sar.v1n2p57

URL: http://dx.doi.org/10.5539/sar.v1n2p57

\begin{abstract}
In order to be meaningful, agricultural research has to provide solutions to problems, especially in the international agricultural research system which is designed to contribute to enhanced food production and improved rural livelihoods in the lesser-developed world. Training and human resource development, whether at the technical support or research scientists/managerial level, is fundamental to an effective agricultural research and technology transfer system. By comparison with the developed world, the national agricultural research systems (NARS) in developing countries are weak, often with ineffective extension programs, as typified by the West Asia-North Africa (WANA) region, which is served by the International Center for Agricultural Research in the Dry Areas (ICARDA). Despite the potential benefits of enhancing human skills, training and human resource development activities are often under-valued and under-funded in international research centers that serve developing countries. By highlighting training at ICARDA and its mandate countries, we sought to give renewed focus on this important component of the mission of the Consultative Group on Agricultural Research (CGIAR). In this article, we considered ICARDA's philosophy and concepts on training, collaborating institutions, educational materials, categories of training, development of training courses, significant outcomes of training, shifting paradigms, and future directions. ICARDA's innovative collaborative approach is a model to be emulated not only by the Centers but by other international institutions involved in agricultural and rural development in the developing countries. At this crucial time of restructuring of the CGIAR, renewed emphasis on training has never been more urgent.
\end{abstract}

Keywords: agricultural development, international agricultural research centers (CGIAR), enhancing human resources

\section{Introduction}

Following a century of continuous breakthroughs in agricultural research and its application at farm level, with phenomenal increases in agricultural output, particularly in the developed countries of West, the complacency about world food supplies has now given way to disquieting concerns about mankind's capacity to feed itself (Borlaug, 2007). The Malthusian elements of the 19th century have begun to reassert themselves, driven by unrelenting population growth, especially in developing countries. With limited possibility for arable land expansion, the only alternative is improved agricultural practices that are both intensive and sustainable (Tilman et al., 2002). Achieving the goal of enhancing agricultural and rural sectors in developing countries is complex, both from the biophysical and social perspectives.

The challenges facing agronomists to tackle global hunger have been highlighted for decades (Kirkwood et al., 1973), with various solutions to technology transfer to small scale-farmers proposed (Brams et al., 1980; Tindall et al., 1984). The need to understand the socioeconomic circumstances of small-scale farmers was seen as a necessary condition for effective development efforts (Rhoades, 1984). A major thrust of such development has been on education of scientific and technical staff from developing cultures, with considerable debate as to the appropriateness of conventional advanced degrees in western academic institutions (Cashman \& Plihal, 1987; Brams, 1978; Cooper \& Cashman, 1985).

While research and graduate training was seen as a basis for promoting change in traditional agriculture, such training was deemed more effective if it was within the context of developing countries (Rohweder et al., 1972. A hybrid approach to such training involving partial study abroad, i.e., course work with in-country thesis 
research (Ryan et al., 2007), is now seen as more relevant to development, with corresponding changes in host-country institutions that deal with agricultural research, education and extension (Murdoch et al., 1972; Tripp \& Anandajayasekeram, 1990; Shroyer et al., 1992). A consensus has emerged that there is a greater need to understand the context and circumstances of future scientists and leaders in agricultural development prior to submitting them to advanced education programs (Caddel, 1991).

While many international and national institutions, both public and private, have agricultural development agendas to varying degrees, a major entity in development in the past few decades has been the international network of research centers sponsored by the CGIAR. The goal of this network of global centers (Figure1), mainly located in developing countries, is to mobilize international scientific resources in order to underpin relevant and applied research initiatives to boost food resources and enhance the quality of life for the world's 1 billion poor and hungry people (Deane et al., 2010).

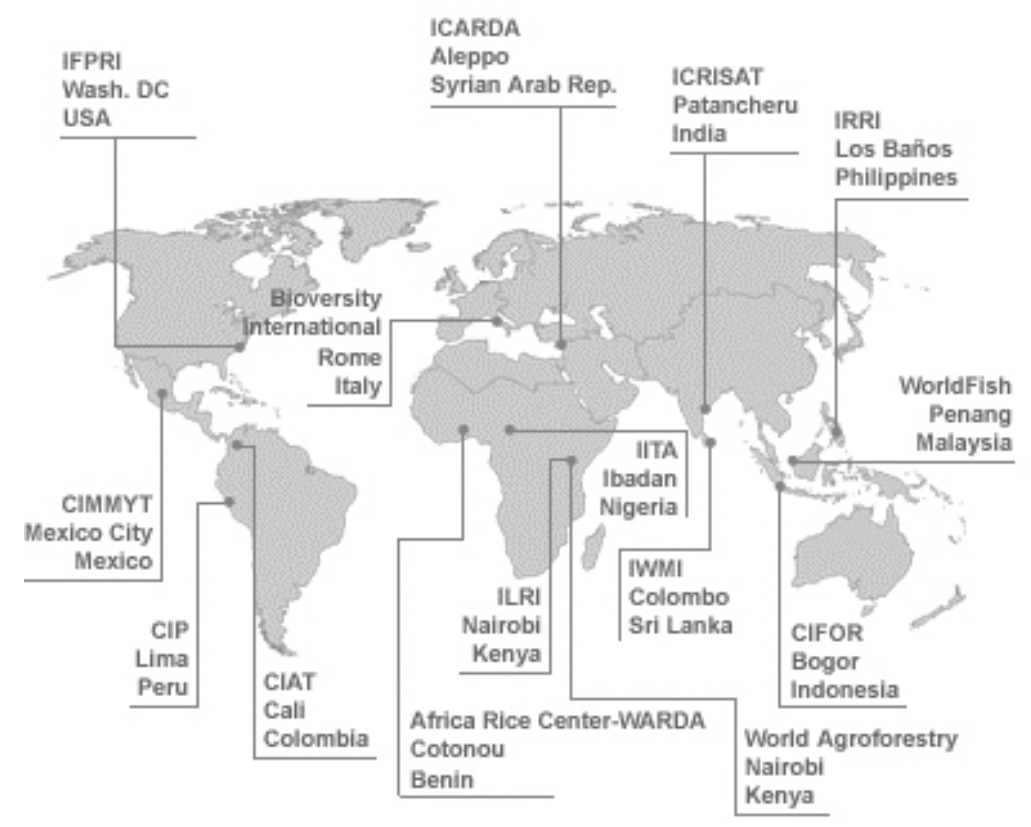

Figure 1. Worldwide distribution of the international centers of the Consultative Group on International Agricultural Research (CGIAR)

While various approaches have been adopted to further the CGIAR goals, including networking with national agricultural research systems (NARS) of the mandate countries (Ryan et al., 1995; van Schoonhoven, 1991), training and capacity building has been given variable emphasis by the international centers (generally ranging from $3 \%$ to $25 \%$ of its budget) despite the obvious potential for impact at the national level (CGIAR, 2006). In the early years following establishment, centers such as the International Wheat and Maize Center (CIMMYT) in Mexico placed considerable emphasis on training (25\% of budget) and its assessment of its wheat program (Swanson, 1975a; Villareal \& de Toro, 1993a;1993b), while research training at the International Rice Research Institute (IRRI) in the Philippines was given prominence (Swanson, 1975b). One report from the International Livestock Research Institute (ILRI) in Ethiopia (Eley et al., 2003) concluded that advanced agricultural science training in Africa can provide a vital process of human and institutional development. Regrettably, in an era of donor-driven funding, areas such as training are poorly supported and cannot compete with more "upstream" areas of research such as biotechnology for donors' scarce dollars.

Over the last three decades, funding of training in the CGIAR changed from core to predominantly specific-project funding. In most centers, this has led to a diminished role of training units and decentralization of training to researchers. Only 7 out of 15 Centers now have staff with any qualifications in training, pedagogy or adult education (CGIAR, 2006). Despite the decreased emphasis on training and capacity building in the CGIAR system as a whole, ICARDA, which focuses on Mediterranean-type agricultural ecosystems, primarily in the West Asia and North Africa (WANA) region, is one center that has maintained a significant training component. 
ICARDA operates in a fragile Mediterranean environment (Kassam, 1981) with a complex cropping system adapted to drought conditions (Cooper et al., 1987). The region is fraught with political tensions and potential conflicts regarding natural resources (El-Fadel et al., 2003), as well having inherent constraints for technology transfer (Chaudhry \& Ryan, 1983). From its inception in 1977, ICARDA has had an active role in enhancing the research capacity of the NARS. The Center recognized that quality research cannot be achieved without a well trained cadre of scientists and support staff in national programs who are conversant with research issues of relevance to the region.

Consequently, in this article we sought to highlight the unique features of the Training Program at ICARDA and to show how it addressed the challenging conditions impinging on the countries in the WANA region, most of which are food-deficit and beset with biophysical and socio-cultural constraints to development. A fundamental aspect of the Training Program is that it responds to the needs of the region's NARS, and is largely defined by them. Aspects of training that are considered include: 1) underlying training philosophy, 2) training categories, 3) educational materials, 4) training course development, 5) changing themes, 6) collaborating institutions, 7) participants in training, 8) specific examples of capacity development in the NARS of the Center's mandate region, with examples from Pakistan (rural livelihoods), Afghanistan (seed improvement), and Morocco (biotechnology), 9) training program assessment, and 10) future perspectives. The article concludes with a plea for increased emphasis on training and capacity-building to enhance technology transfer efforts of international agricultural development institutions.

\section{Training and Capacity Building at ICARDA}

\subsection{Basic Concepts and Philosophy}

While the philosophy of training applies to wide range of educational and development institutions, many of those concepts are germane to ICARDA's Training Program. Being an intrinsic part of the Center's research and development efforts, the following points with regard to training are particularly relevant: 1) Training needs are mission-driven and needs-based, consistent with the institution's core capabilities, and based on a comparative and competitive advantage. 2) Impact at farm or rural level is a common goal of training efforts. 3) Its organization principle is based on partnerships, networking and collaboration. 4) Transparency and accountability, scientific integrity, professional excellence, and quality assurance are core principles. 5) Technology generation at the research center level is complementary with impact adoption at farm level. 6) Continuous education is the basis for sustainable development. 7) A multifaceted approach based on best practices in education and training using modern information communications technology is needed. 8) We must realize that the trainees of today may be tomorrow leaders.

\subsection{Training Materials}

To further its training-education agenda, ICARDA has developed and produced a range of communication media. The process of developing such materials has been an on-going one, involving testing, adapting and implementing of innovative approaches, and delivery mechanisms. These materials are designed to support formal lectures or stand alone for individualized learning. The range of educational materials includes: printed manuals, field and laboratory guides, audio-visuals and photo collections, and e-materials on educational resources, virtual laboratory and field products, and e-tutorials. Broad topics covered by the Training Program include: plant breeding and associated biotechnology skills, agricultural socio-economics, integrated land management, conservation agriculture, crop-range-livestock integration, skills in geographic information system (GIS), and internet communications technology.

Some examples of specific training materials are relevant to demonstrate the range and depth of instruction in the Program. Major book-size manuals include the soil and plant analysis manual that was produced in a first (Ryan et al., 1996) and subsequent edition (Ryan et al., 2001) and translated into Arabic and Russian. Another soil-related manual that underpinned many training courses was the soil characterization of ICARDA's experiment stations (Ryan et al., 1997), as identification of soil types (and associated environmental factors) is essential to validly out-scaling station research. A major training book that backstopped microbiology-crop courses was the Center's rhizobium-legume technology manual (Beck et al., 1993). Other written manual-type publications addressed food legume physiology, grazing management, seed quality control, morphological variety description, seed processing, economics of seed production, statistical analysis, and legume quality analysis. Written modules were developed for seed health, biological nitrogen fixation, and hybridization techniques in food legumes, and lentil harvesting.

In addition to written materials, a computer database ("Seed Man”) was developed for seed-stock inventory and control, and a video on seed processing. The most recent educational development was ICARDA joining the 
CGIAR Online Learning Resources (OLR) portal site on the World Wide Web that provides access at a simple location to all learning resources maintained by individual centers, e.g., http://learning.cgiar.org.

Fundamental to any training program involving the NARS is a well-trained, well informed staff involved in such training from the Center itself. In an ever-changing environment, staff members who backstop ICARDA's Training Program require continuous upgrading of their skills, particularly in computer and information technology. Opportunities for staff development range from short internal courses (computer applications, knowledge management, statistics, management applications, log frame, safety regulations) to internships outside as well as language courses (English/Arabic). As in research, it is imperative for staff involved in aspects of training to remain at the cutting-edge of developments related to the process of training as well as the relevant technical aspects.

\subsection{Innovative Approaches}

Various approaches have been adopted to enhance the value of training, especially in the area of seeds. A functional seed delivery system is a prerequisite for effective adoption and achieving a higher rate of return from investments on variety improvement. Consequently, the Center has a Seed Unit aimed at strengthening the seed delivery systems of its national partners through capacity-building and training. The Unit diversified its training approaches to address the challenging task of providing quality training to a large number of countries at varying stages of seed sector development, market orientation levels, and socio-economic context.

During the last three decades, some countries from the ICARDA geographic mandate region embraced national seed system diversification through policy changes that promoted private investment in the seed sector. Two models of seed-system diversification were adopted depending on the level of seed sector development. Some countries with an advanced national seed sector, e.g., Turkey, Pakistan, Sudan, and Egypt, adopted seed market liberalization, whereas other countries such as Ethiopia and Afghanistan opted for decentralization of the national seed sector by promoting farmer-based seed production and marketing. To cope with the extensive capacity-building and training requirements of its national counterparts arising from the seed sector restructuring processes, innovative approaches were adopted, a process that reflected a change in donor funding.

In the 1990s, at a time when many of the world's leading seed science and technology training programs were declining, training demands from ICARDA's national partners increased with respect to a wide range of technical, managerial, economical, and policy subjects related to seed-system development and diversification. To cope with such training needs, the Seed Unit adopted a "Train-the-Trainers" approach as an innovative training concept with a multiplier effect. The concept, being based on decentralization and being participatory and action-oriented, was implemented through a 4-year training project (1997-2001) funded by the Netherlands Directorate-General for International Cooperation. The project was implemented through organization of a series of regional "mother" courses on the main seed system development and diversification. Potential future trainers from different countries were invited to participate in such courses based on their commitment to organize a pre-determined number of follow-up courses at the national level. The declining technical and financial support from ICARDA had to be balanced with a corresponding increased contribution from the respective national programs. During the project, 716 seed specialists at technical and managerial levels from 12 countries of WANA were trained on the major seed science and technology disciplines.

\subsection{Categories of Training}

In the early years of ICARDA, most of the training courses were conducted at its headquarters at Tel Hadya, near Aleppo in northern Syria. Increasingly, with development of the various regional programs, a greater proportion of the courses were conducted in those countries. A wide range of training is provided to staff from the national programs. These courses range from short specific courses to long-term degree courses in collaboration with degree-giving universities, and from traditional courses to ones based on advanced technology (Table 1). Some elaboration on the training categories is pertinent.

\subsubsection{Group}

Specialized intensive short courses (1-4 weeks) conducted at Tel Hadya or other locations focus on themes or topics of interest to the national agricultural research programs. These courses can be regional, sub-regional, or in-country. Courses are held at headquarters during the cropping season and are designed for researchers and technicians currently working in the NARS. Course participants should have a BSc or diploma in agriculture.

\subsubsection{Individual Degree}

This type of training hosts mostly NARS employees undertaking M.S. or PhD studies who are required to work on a project related to existing research protocols for a period of up to 3 years. Center scientists identify projects 
within their existing or planned research protocols that are suitable for Graduate Fellows. The institution strives to select the best and most appropriate applicant, considering both academic excellence and their ability to further ICARDA's collaboration and research goals. Such degree based research is a major complement to the Center's research program.

Table 1. Selected traditional and advanced technology training courses at ICARDA

\begin{tabular}{l}
\hline Traditional \\
\hline Water Harvesting and Supplemental Irrigation \\
Improving Water-Use Efficiency in Agriculture \\
Scientific Writing and Data Presentation \\
Integration Management of Cereal/Legume Pests \\
Soil and Plant Analysis \\
Farming Survey Methodology \\
Seed Health Testing \\
Gender Development \\
Advanced Technology \\
Remote Sensing and GIS in Land Evaluation \\
DNA Molecular Marker Techniques for Crop Improvement \\
Molecular Characterization for Biodiversity Studies \\
In vitro Biology/Transformation Technology \\
Utilization of Expert Systems in Agricultural Research and Production \\
\hline
\end{tabular}

\subsubsection{Individual Non-Degree}

Non-degree training focuses on harnessing the skills and abilities of individuals to contribute to the realization of developmental goals and is offered to junior researchers, tailored to meet individual needs, and may range in duration from $1 \mathrm{wk}$ to $1 \mathrm{yr}$. This program also offers interns for senior researchers from NARS, who typically have an M.S. or PhD and several years of experience. They work at headquarters or elsewhere in the outreach regions with ICARDA scientists for a few weeks to months on research or to receive specialized training. A great deal of training is linked to specific collaborative research projects or responds to specific demand from national programs.

\subsection{Course Development}

Unlike universities, where fixed courses are offered on a fixed-time schedule, training courses at ICARDA, whether at headquarters or in outreach, are flexible and depend on the perceived need, the funding available; and qualified personnel to teach such courses. A general flow chart (Figure 2) common to most international centers indicates the various stages in the process of developing training courses; identifying course needs by the NARS and initiated at the regional coordination meetings, funding sources, budget plans and approval, developing the appropriate course content, participant selection, implementation of the approved course, evaluation and follow up. Depending on the instructors and the particular course, most courses have some form of assessment, either direct or indirect. For financial and other logistical or cultural considerations, detailed follow-up assessment of courses through questionnaires is rare Whatever feedback is obtained during or at the end of the course is invariably considered in deciding on future course offerings or in modifying existing courses. Where courses are repeated in subsequent years, the development steps may vary, in most cases with updating of course contents. 
Needs for specific courses identified by national agricultural research systems (NARS),

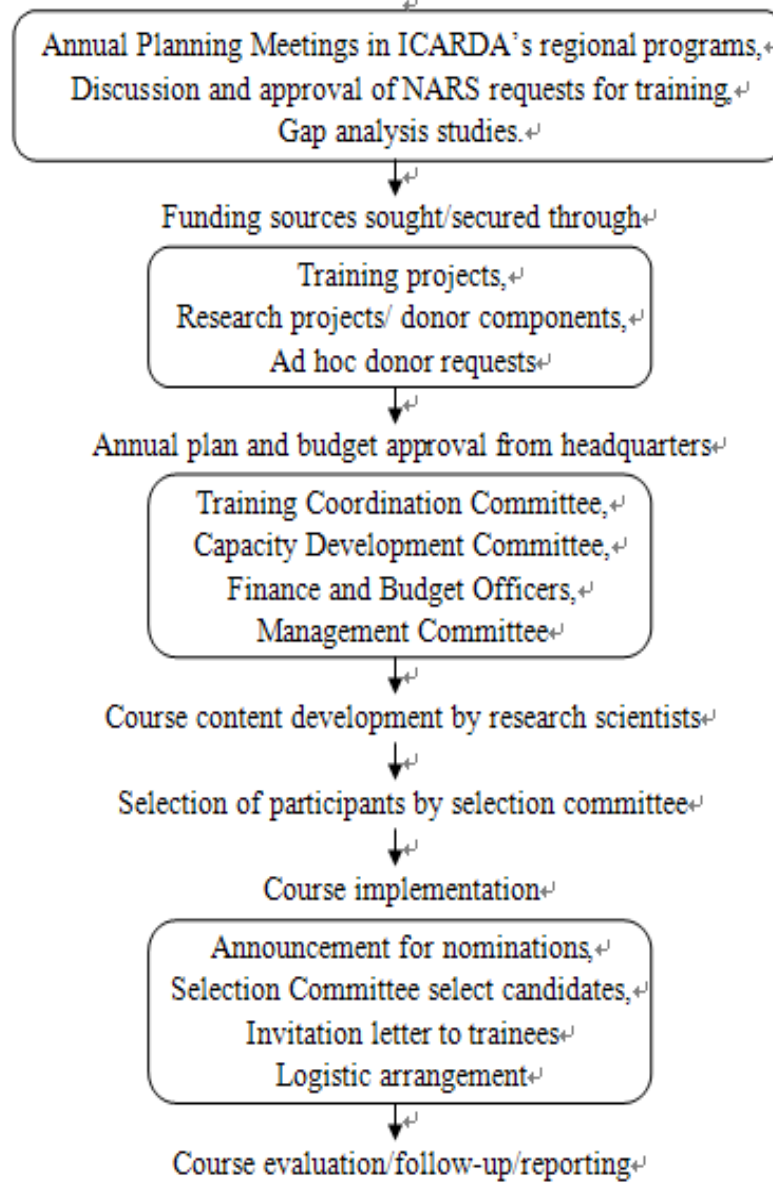

Figure 2. Steps in the development of courses at ICARDA

\subsection{Themes and Shifting Paradigms}

ICARDA has conducted several general or "traditional" courses that address broad issues of continued relevance to the research priorities of the institution that are developed with the concerned agricultural organizations in the various countries of its mandate region. Given the overwhelming importance of water, or the lack of it, in the WANA region, courses on water-use efficiency and management remained important. An annual course sponsored by the Japanese Development Agency that covered a wide spectrum of issues related to water, being generally given to 20-30 participants from countries of the region.

As the Center's research agenda evolved, so too did the demand for courses that centered on advanced technology. Inevitably, the institution's changing priorities and a trend towards more sophisticated research approach and methodologies led to changes in course offerings, with decreased emphasis on some areas where tangible progress had been made, to areas where there was a pressing need to expand existing courses or offer new ones, such as biotechnology, GIS, and biometrics (Table 2). In essence, since the early days of ICARDA's existence (founded in 1977), the training program changed in response to the articulated training and capacity-building needs of the NARS of the WANA region. A significant feature of the suite of courses in the program was the devolution from the headquarters at Tel Hadya to the region's national programs. Chief among these trends was the shift to "decentralized" cereal breeding, along with a general trend of courses away from headquarters to regional programs, with a shifting away from long-term programs. With the termination of most of the Center's long-term trials, diminished importance was given to courses centered on such cropping systems trials. 
Table 2. Training shifting paradigms in response to changing research programs of ICARDA

\section{Decreased Emphasis}

High rainfall area agronomy, In-house finished cultivars, Wheat/medic systems, Rhizobium evaluation, Software development, Cereals with assured moisture

Increased Emphasis

On-farm water management, Rangeland management and rehabilitation, Biometrics, Livestock, Agro-ecological Characterization, Utilization of Non-Conventional Water Resources, Geographic Information Systems, Expert systems for technology transfer, Biotechnology for crop improvement, Information management, Soil and land conservation, Farmers' participatory approaches, Land/water resources Management, Biotechnology and genetic engineering.

Transferred Emphasis

Centralized to De-centralized breeding; Headquarters (Tel Hadya) crop rotation trials to less elaborate trials (on-station and on-farm) at individual country level; Integrated pest management (IPM) screening in isolation to integrated pest management in systems; Headquarter courses to outreach courses in mandate countries; Long-term to short-term and individual degree and non-degree training

\subsection{Collaborating Institutions: Regional and International}

By virtue of its mandate, ICARDA functions principally in partnership with the WANA region's agricultural research system, often with the involvement of advanced institutions around the world. In that respect, the training component of ICARDA reflects the institution as a whole. Many institutions contribute technically to the course content and teaching, as well as funding. In the latter respect, funding for training, which was traditionally supported by core funding, has paralleled a trend in the institution as a whole from being supported by core funds to specific-project funding.

While the institutions that have contributed to varying degrees to training and capacity development are many, a sampling of such institutions is presented to reflect the type of institution and its geographic location (Table 3). These range from the Tottori University, Japan; American University of Beirut, Lebanon, University of Aleppo, Syria; Agricultural Research Center, Libya; Center for Legumes in Mediterranean Areas to the Mediterranean Development Institute (CIHEAM), and to the International Fertilizer Development Center (IFDC) in the USA. The relative importance and contributions of such international partners is constantly evolving.

Table 3. Some collaborating institutions in training

\begin{tabular}{l}
\hline Some collaborating institutions in training \\
\hline CIHEAM (Bari, Italy; Zaragosa, Spain);World Meteorological Organization (WMO), Geneva; Center for \\
Legumes in Mediterranean Areas (CLIMA), Perth, Australia; Bioversity International, Rome, Italy; Arab \\
Center for Studies of the Arid Zones and Drylands (ACSAD), Damascus, Syria; International Fertilizer \\
Development Center (IFDC), Alabama, USA; Arab Planning Institute (API), Kuwait; Egyptian International \\
Center for Agriculture (EIEA), Cairo, Egypt; International Program for Agricultural Knowledge Systems \\
(INTERPAKS), Illinois, USA; Tottori University, Japan; Wageningen University, The Netherlands; American \\
University of Beirut, Lebanon; University of Aleppo, Syria; University of Damascus, Syria; United Nation \\
University, USA; Zurich University, Switzerland; Agricultural Research Center, Libya; Institut National \\
Agronomique, Tunis.
\end{tabular}

\subsection{Training Participants}

A crude measure of training since ICARDA's inception is the total number of participants in the various training programs (Table 4). The increase in numbers of participants reflected the pace of growth and development of the institution, with consistent increases in the number of participants in the 1980s, being relatively stable from then onwards. In essence, the sustained demand from the national programs for training courses are testimony to the effectiveness of the training courses being offered. In short, the demand was client-driven. Almost half of the total participants were involved in short-term non-headquarters courses, with a sizeable number still involved in such courses at Tel Hadya. 
Table 4. Number of training participants and category of training at ICARDA

\begin{tabular}{|c|c|c|c|c|c|c|}
\hline Year & $\begin{array}{l}\text { Headquarters } \\
\text { Long-term }\end{array}$ & Short-term & $\begin{array}{l}\text { Non- Headquarters } \\
\text { Short-term }\end{array}$ & $\begin{array}{l}\text { Individual } \\
\text { Non-Degree }\end{array}$ & $\begin{array}{l}\text { Individual } \\
\text { Degree }\end{array}$ & Total \\
\hline 1978 & 26 & - & - & - & - & 26 \\
\hline 1979 & 45 & 19 & - & - & 2 & 66 \\
\hline 1980 & 42 & 6 & - & 4 & 3 & 55 \\
\hline 1981 & 18 & 13 & 14 & 6 & 4 & 55 \\
\hline 1982 & 24 & 49 & 40 & 6 & 6 & 125 \\
\hline 1983 & 52 & 34 & 35 & 6 & 1 & 128 \\
\hline 1984 & 25 & 60 & 91 & 23 & 4 & 203 \\
\hline 1985 & 41 & 52 & 77 & 40 & 13 & 223 \\
\hline 1986 & 70 & 58 & 176 & 71 & 22 & 397 \\
\hline 1987 & 54 & 65 & 90 & 69 & 35 & 313 \\
\hline 1988 & 59 & 78 & 337 & 77 & 39 & 590 \\
\hline 1989 & 55 & 109 & 211 & 113 & 37 & 525 \\
\hline 1990 & 44 & 179 & 340 & 90 & 40 & 693 \\
\hline 1991 & 16 & 216 & 372 & 96 & 44 & 744 \\
\hline 1992 & 16 & 171 & 371 & 113 & 45 & 716 \\
\hline 1993 & 14 & 111 & 394 & 83 & 57 & 659 \\
\hline 1994 & 12 & 102 & 294 & 81 & 63 & 552 \\
\hline 1995 & 10 & 84 & 465 & 90 & 68 & 717 \\
\hline 1996 & 11 & 146 & 369 & 84 & 58 & 668 \\
\hline 1997 & 9 & 140 & 504 & 98 & 65 & 816 \\
\hline 1998 & - & 171 & 521 & 106 & 67 & 865 \\
\hline 1999 & - & 207 & 353 & 87 & 71 & 718 \\
\hline 2000 & - & 152 & 289 & 106 & 68 & 615 \\
\hline 2001 & - & 111 & 349 & 83 & 63 & 606 \\
\hline 2002 & 22 & 91 & 291 & 102 & 54 & 560 \\
\hline 2003 & 28 & 139 & 270 & 64 & 51 & 552 \\
\hline 2004 & 23 & 109 & 624 & 58 & 44 & 858 \\
\hline 2005 & 24 & 327 & 723 & 50 & 54 & 1178 \\
\hline Total & 740 & 2999 & 7600 & 1806 & 1078 & 14223 \\
\hline
\end{tabular}

It is illustrative to examine the relative importance of the various themes in the overall short-term offerings. Data for the recent 5-year period (Figure 3) indicate the importance of courses related to seeds, followed by those related to water and crop breeding. As expected, a breakdown of the nationalities or regions from which the participants came (Figure 4) shows a dominance of the Central Asia and Caucasus region and countries of West Asia, with relatively fewer from the Nile Valley (Egypt, Sudan, Ethiopia, Eritrea) and North Africa (Morocco, Libya, Algeria, Tunisia). Relatively smaller numbers of training participants were from other regions.

\subsection{Post-Graduate Degree Training}

A core function of ICARDA is the provision of facilities to junior staff from the region's NARS to conduct field and laboratory research under supervision of its staff, but in association with degree-granting universities. While data are available for the entire period of ICARDA's existence, details for a 5-year period (2004-08) reflect the dominance and growing importance of crop improvement as the major area of emphasis (185 trainees), with minor importance of water and land management (44), diversification of crops and cropping systems (31), socioeconomics (17) and geographic information systems (5).

A wide range of research topics have been addressed in graduate studies, with a total of 605 degrees based on research at ICARDA been granted over the last 3 decades. While the list is lengthy, the thesis topics indicate a 
wide diversity and a range of associated institutions (Table 5). The topics have embraced broad issues such as agro-ecological characterization, conservation agriculture, crop rotations, nutrient dynamics, stress tolerance breeding, crop diseases, remote sensing, molecular markers, socio-economics of farming systems and gender issues. The thesis topics reflect the overall diversity of research within the institution.

Table 5. Selected MSc/PhD theses and respective universities (1995-2009)

\begin{tabular}{lll}
\hline Women, Agricultural Labor, Decision-Making & Reading & UK \\
\hline Socio-economics of Bedouin Farming Systems & Hohenheim & Germany \\
Use of Remote Sensing in Water Harvesting & Karlsruhe & Germany \\
Cyst Nematode in Cereals & Bonn & Germany \\
Boron Dynamics in Saline Soils & Baghdad & Iraq \\
Seed Storage Protein Genetic Variability & Cordoba & Spain \\
Vicia Amphicarpa in Marginal Lands & UWA & Australia \\
Trifolium Regeneration in Ethiopian Highlands & Montpellier & France \\
Economic Analysis of Sheep Market in Syria & Aleppo & Syria \\
Milk Yield and Lamb Growth of Syrian-Awassi Sheep & Çukurova & Turkey \\
Intensification on Small Ruminants Milk Quality & BOKU & Austria \\
Marker-Assisted Selection for Barley Disease Resistance & Aleppo & Syria \\
Informal Wheat Seed System of Iran & Wageningen & Netherlands \\
Improving Small Ruminant Productivity & ETH Zurich & Switzerland \\
\hline
\end{tabular}

UWA $=$ University of Western Australia

As biotechnology has emerged as a tool with considerable potential to contribute to food security, the efforts in this area of research and associated training merit some elaboration. Initially, biotechnology research had been constrained by a lack of trained staff, suitable laboratory facilities, specialized equipment and technical expertise. ICARDA responded to this by focusing efforts on building the research capacity in national programs on the use and application of biotechnological tools, including various levels of targeted training in addition to benefits from scientist-to-scientist exchanges and involvement in collaborative programs. During 2007-2009, there were a total of 241 direct beneficiaries of capacity-building activities, including young researchers, students, junior level scientists, and technicians from 30 different countries.

This training effort in biotechnology resulted in much wider adoption of biotechnology tools within co-operating national agricultural research programs, and molecular markers are now being applied. Biotechnology uses include: molecular characterization and diversity analysis (drought tolerance, salt and heat stress), molecular marker-assisted backcross breeding (enhanced water-use efficiency, pest and disease resistance, increased yield and quality), integrating the doubled-haploid technique with molecular marker-assisted selection to speed up variety development, and improved in vitro regeneration protocols for genetic transformation. An integrated multidisciplinary approach across national and regional centers, universities and advanced research institutions has ensured that various biotechnological tools are now being applied to address specific problems in crop production due to drought, pests, salinity, and genetic erosion.

Degree-level training in biotechnology was given at ICARDA headquarters to 19 students in 2007-2009, including 12 to $\mathrm{PhD}$ level, from Ethiopia, Jordan, Iran, Iraq, Morocco, Sudan, Syria and Tunisia, and seven to MSc level from Syria. Individual non-degree level training in molecular marker applications, double-haploid production and genetic engineering was also received by 42 trainees from Algeria, Bangladesh, Ethiopia, Germany, Iran, Iraq, Jordan, Lebanon, Libya, Pakistan, Qatar, Syria, Tunisia, Turkey and Yemen. Six 12-day training courses were held at ICARDA during the same period, on molecular characterization and genetic improvement (crops and small ruminants). Trainees (102) attended from Algeria, Armenia, China, Egypt, India, Iran, Iraq, Jordan, Kazakhstan, Lebanon, Libya, Morocco, Oman, Pakistan, Palestine, Qatar, Sudan, Syria, Tunisia, Turkey, Uzbekistan and Yemen. In addition, four in-country training courses were conducted in Iran, Morocco and Oman and (52 trainees), covering biotechnology, biosafety, in vitro culture and statistical analysis, 
with two courses specifically on date palm and wheat.

\subsection{Capacity Development at Country Level}

A major thrust of the socioeconomic program on poverty, livelihood analysis, impact assessment at ICARDA has been concerted capacity development within certain countries at regions in Central, West Asia and North Africa (CWANA). The programs are worthy of note.

\subsubsection{Rural Livelihoods in Baluchistan, Pakistan}

The rural development project in Pakistan (ICARDA, 2009) sought to improve the livelihoods and food security of the rural people of Baluchistan by strengthening the province's applied research and technology delivery system to provide a sustainable market-oriented arid agriculture through livestock marketing, crop productivity, and agro-processing. The extensive program involved training of 147 staff from provincial institutions, mainly the Arid Zone Research Center, as well as 82 farmers trained on aspects of seed production, animal health and nutrition, and crop improvement.

The training activities involved in furthering the Project's goals included three training workshops. The applied research focused on capacity building of national staff in generating community-tested options that improve on-farm water resources management, enhance livestock production and rangeland management, improve economic return through cropping diversification, add value locally to commodities from indigenous production and improve market accessibility.

A workshop on assessing research impact on rural livelihoods was organized to train facilitators to act as catalysts between research components and rural communities. The facilitators were instructed in data collection for studies related to soils, crops including horticulture, range, livestock, role of women, community organization, leadership roles and conflict resolution.

A training module was conducted at the Tarnab Agricultural Institute in Peshawar, North West Frontier Province, for women in the Agricultural Research Institute in Quetta, Baluchistan. In addition to the training of provincial staff, the most tangible outcome was increased household income in the Project-targeted communities and increased output of women's cottage industries.

\subsubsection{Crop Improvement/Seed Technology in Afghanistan}

Afghanistan has been devastated by conflict for decades and plagued by drought, with negative impacts on its agriculture and society as a whole. The country requires substantial humanitarian, rehabilitation and construction assistance to regain its food security and to tackle poverty. To that end, ICARDA, assisted by funding from the Japan International Cooperation Agency, conducted a series of training courses for staff from Afghanistan and other war-ravaged countries of CWANA in plant breeding, genetic resources management, biotechnology, seed health and seed system development (ICARDA, 2010).

A follow-up study on the effectiveness of training revealed that most of the ex-trainees used the training to disseminate knowledge to their colleagues, extension workers or farmers. The explanation given was that most of them were in leading positions such as chief researcher or head of a section or teaching. Therefore, it was easy and possible to disseminate their knowledge to others when they returned from the training to Afghanistan. Another reason was that, in Afghanistan, returning trainees are expected to be trainers to the others. In fact, the dissemination of knowledge was not only thorough providing training or seminars but also implementing research experiments and thus training staff on-the-job and hands-on.

Conducting experimental research using up to date knowledge and skills was a good example for their colleagues on the site. In other words, ICARDA's training was creating "training-of- trainer" opportunities. Anecdotally, most of the ex-trainees emphasized the importance of capacity-building for government officials in the agricultural sector who sought to expand the opportunity to embrace international standards. Some of the ex-trainees expressed the necessity of a modern irrigation system for water saving.

The lessons learnt from the "Train-the-Trainer" project have been replicated in Afghanistan through the CGIAR "Future Harvest" consortium to rehabilitate agriculture in Afghanistan. By 2003, 1555 Afghan researchers, extension personnel and farmers had been trained in the major agriculture disciplines such as field crops and potato seed production, crop improvement and management, income diversification, and integrated pest management (Varma \& Winslow, 2004).

\subsubsection{Seed Delivery Systems in Ethiopia}

Bridging the gap between demand and supply in quality seed has been a priority for boosting agricultural production and productivity to achieve food security in Ethiopia. The farmer-based seed production scheme is a 
cornerstone of efforts to fill the gap between the demand for seed and the supply (Thijssen et al., 2008). This huge task required the participation of the major stakeholders from both the federal and the regional states. Cognizant of this, the Ethiopian Seed Enterprise and its partners, Wageningen International (The Netherlands) and ICARDA developed and implemented a project aimed at improving farmer-based seed production and revitalizing the informal seed supply of local crops and varieties in Ethiopia. The tailor-made training program that followed a multi-stakeholder process and participatory approaches engaged participants in a process of learning and action research. The 1-year program went through the following stages:

- Building a core group of participants from various federal and regional institutions (acquiring knowledge and integrating theory with practice).

- Diagnostics of the regional seed system and design of alternative schemes translating knowledge into action.

- Presentation and discussion of diagnostic results with stakeholders in regional workshops.

- Implementation of the first farmer-based seed activities.

- Organization of a national seed policy workshop on rationalization of policy and regulatory framework.

- A regional workshop in which participants presented experiences of farmer-based seed approaches from Ethiopia, Africa, and Asia related to genetic resources' conservation, participatory crop improvement and local seed supply.

The capacity building and training activities of the "tailor-made training program", were comprehensively documented and compiled (Thijssen et al., 2008) and covered technical, managerial and policy in seed science and technology. The program reflected the potential impact on the Ethiopian seed system development and diversification.

\subsubsection{Biotechnology in Morocco}

Given the relative newness of biotechnology as a tool for crop improvement, and its potential for impact, considerable emphasis was placed on this technology, and donor funding was secured. With respect to biotechnology, one example of country-specific benefits is ICARDA's collaborative work on capacity building under the Morocco Cooperative Grant Program. Under this program, a scientist from ICARDA was also placed at the Institute National de la Recherche Agronomique (INRA), Morocco, for capacity-building and institutional backstopping. The grant program trained young researchers, students, junior level scientists, and technicians. A group training course and individual training programs were conducted. Individual specialized training courses of 2-6 months duration were completed by three young scientists from INRA-Morocco and eight students from Moroccan universities or training institutes. The joint training courses also stimulated most of them to complete their degrees, including four MS, five 'Maitrise' and one $\mathrm{PhD}$ in biotechnology, under the co-supervision of ICARDA and Moroccan scientists

The joint NARS/ICARDA training efforts resulted in the adoption of biotechnology tools by researchers at INRA-Morocco. Molecular markers are now being used for the genetic diversity analysis of wheat (Triticum aestivum L.), olive (Olea spp), sugar beet (Beta vulgaris) and alfalfa (Medicago sativa), now being extended to other crops. Molecular marker techniques were applied to identify and characterize rhizobia of the legume crops, resulting in the development of drought, salt and heat stress tolerant strains. Moroccan NARS were also able to obtain new grants from the International Center for Genetic Engineering and Biotechnology, the Generation Challenge Program and the Arab Science and Technology Foundation, to continue biotechnology research activities, as a result of ICARDA facilitation and capacity building.

\subsection{Assessment of Program Activities}

The capacity strengthening activities of ICARDA are implicit and measurable to the extent of numbers completing the various training activities. However, evaluation of long-term impact with conventional impact studies of training is problematic. While the Center is committed to institutionalizing a comprehensive planning, monitoring and evaluation system, there was little support from decision-makers and trainees, who were not required to report on their long-term human resource development activities. Evaluation of training was given low priority in many educational and training institutions (Marsden, 1991). The focus of the impact assessment should be on the value of the overall learning experience and its contribution to individual and organizational development (Senge, 1995). However, a major difficulty is that assessments are made by training managers mostly on the basis of evaluating the training activity itself and not the important subsequent outcomes (Foxon, 1989). Consequently, less is published about the impact of degree training than the evaluation of the 
effectiveness of training methods.

Impact studies using quantitative techniques are few due to limited financial resources and trainer's expertise (Foxon, 1989; Marsden, 1991). For those tools that do exist, emphasis has often been placed on the tools themselves, while paying little attention to setting out clear objectives and research questions or hypotheses for the evaluation. In other words, the tools determine rather than provide the service to the outcome. The major difficulty is to separate the attribution due to training by ICARDA from that caused by other events, e.g., institutional policy changes, other training, self-learning, Internet use, visits, etc.

A review of evaluation methods in education and training program identifies three main techniques: 1) direct interviews that include interviewing the trainee, trainer or trainee's supervisor, 2) the use of questionnaires (without interviews) which generate qualitative or quantitative data or both, and 3) statistical measures that tend to compare an evaluated group of participants with a control group. Some literature does, however, suggest that a mix of methods is preferable to the selection of one of these methods. It is advised, for instance, to combine interviews with questionnaires, and to collect both qualitative and quantitative data (Brannen, 1992; Kirkpatrick, 1994). Approaches to evaluate the impact of its capacity development are dictated by resources, circumstances, and cultural conditions. A recent study from the WANA region involved a 3-week course for extension agents from Iraq (Abi-Ghanem et al., 2009). After each module of the course, trainees were asked to assess various aspects of the course before and after the training sessions; invariably respondents rated higher after exposure to the training. The effectiveness of post-training surveys is limited often limited by a reluctance of trainees to respond critically to items in follow-up surveys and the likelihood of a low, and therefore invalid, return. Longer term assessment is even more problematic due to difficulties of tracking former trainees. In circumstances where formal evaluation is necessary, and as such follow-up requires additional resources, such expenditures should be budgeted in advance.

\section{Conclusions and Future Perspective}

The pace of new knowledge acquisition has never been greater as the boundaries of science are inexorably pushed back; the impetus for development in education and communication will inevitably continue. New approaches will be needed to tackle old but intractable problems that constrain the agricultural sector the WANA region and new problems will emerge to be solved. Capacity building will remain a core priority of ICARDA because of the important role it plays in economic growth and development as well as addressing the rapid changes in the bio-physical, socio-cultural, technological and policy environments of the agricultural innovation systems in the developing as well as the developed world. Formal and informal training activities at ICARDA will continue to be widely conducted to complement ongoing research that is integral to each research theme. Increased emphasis will need to be given on capacity building (ICARDA, 2007), thus reversing a declining trend in recent years.

As science is continuously changing and evolving to meet new challenges, so too does the approach to disseminate scientific findings to the end-users, farmers through the technical cadre that servers the farming sector. Besides traditional approaches, mainly publications and meetings, new ones are increasingly used, e.g., Distance Learning, E-Materials (educational resources, virtual laboratory, e-tutorials), Webinars (WEB-based seminar), Graduate Research Training Program, Sharing Databases, Email, Internet Use, Partner in the CGIAR Knowledge Management Project, and Alumni e-zine.

As in all branches of science, the generation of new technologies in the area of agricultural science is no guarantee that it will be adopted or has impact with the people to improve their livelihood and well-being. While much debate has centered around the existence of widespread hunger and poverty in the developing world (Borlaug, 2007), the key question was why new technologies, or even existing ones, were not being applied in countries and regions of the world where they are most needed. In the face of many less-than-successful educational technology transfer efforts, a consensus emerged that a greater understanding of the socio-cultural as well as biophysical conditions in developing countries was needed.

An essential feature of the CGIAR centers and one that contributed to their success - was that they operated within developing countries and in direct partnerships with developing-country people and institutions (Deane et al., 2010). However, ICARDA has taken an aggressive stance at overcoming obstacles to having impact of its research where it was most needed -with the rural poor. The Center's training and capacity development was unique among international centers to the extent that it reached every level of the NARS of the mandate region, from researchers and educators to farmers themselves. The Center is well positioned to give added value to its research in the future with the adoption of the latest education and communication technology.

The national agricultural systems view training as an indispensable component of the CGIAR's activities. The 
change in funding modality from core to research project funding is putting the weaker national programs at a disadvantage. We stress that issue of funding for training must be addressed. The CGIAR impact study (CGIAR, 2006) recommended that "The shortcomings of short-term funding from the point of view of NARS institutional strengthening must be recognized, and provision made to overcome them as far as possible through integrated, longer term center-NARS-investor cooperation and commitments." Currently, the various stakeholders are restructuring the CGIAR into Mega programs. Capacity building, which serves all Mega programs, centers and partners, is restructured into a cross-cutting platform which will connect with the global agricultural research for development community and contribute to build stronger international agricultural research and educational networks.

In summary, by giving an overview of the training activities at ICARDA, and emphasizing the numbers of trainees from the WANA region and beyond who were the beneficiaries training programs, we hope to make a compelling argument for recognition of the importance of training in international development. The value of the courses offered in the past to staff from the NARS is validated to the continued demand for such courses. We believe that much of the scientific impact of ICARDA in its mandate region can be attributed to its training program. Given the challenges the world faces in feeding its burgeoning populations, there is a pressing need for greatly expanded public support for agricultural research, especially in furthering technology transfer in lesser developed countries. As the CGIAR is now attempting to revitalize its mission, we argue that there should be a renaissance of training and capacity-building in the future agenda of the global CGIAR system in furthering its goals of sustainable research and development.

\section{Acknowledgements}

The authors acknowledge the contribution of Dr. Samir Ahmed and Dr. Lawrence Prezkop, former Heads of Training, the training officers in the research programs, and the staff in the Capacity Development Unit.

\section{References}

Abi-Ghanem, R., Carpenter-Boggs, L., Koenig, R., Pannkuk, C., Pan, W., \& Parker, R. (2009). Extension education for dryland cropping systems in Iraq. Journal of Natural Resources \& Life Sciences Education, 38, 133-139.

Beck, D. P., Materon, L. A., \& Afandi, F. (1993). Practical Rhizobium-legume technology manual. Technical manual No. 19. The International Center for Agricultural Research in the Dry Areas (ICARDA), Aleppo, Syria.

Brams, E. (1978). Educating and training sub-baccalaureate field researchers in developing countries. Journal of Agronomic Education, 7, 49-52.

Brams, E. (1980). Delivery from hunger: A model for the transfer of agricultural technology to small-scale farmers. Journal of Agronomic Education, 9, 57-61.

Brannen, J. (1992). Mixing methods: qualitative and quantitative research. Avebury, Aldershot, UK.

Borlaug, N. (2007). Feeding a hungry world. Science, 318, 359.

Caddel, J. (1991). Improving the education offered international students. J. Agron. Educ, 20, 71 -73.

Cashman, K., \& Plihal, J. (1987). International agricultural students' perceptions of the relevance of their US education. Journal of Agronomic Education, 16, 61-65.

CGIAR. (2006). Evaluation and impact of training in the CGIAR. The Consultative Group on International Agricultural Research Science Council, Washington, D.C., U.S.A.

Chaudhry, M. A., \& Ryan, J. (1984). Constraints to effective agricultural extension in the Middle East region. Journal of Agronomic Education, 13, 89-92.

Cooper, T. H., \& Cashman, K. (1998). International student perspectives of their graduate training in agriculture. Journal of Agronomic Education, 14, 109-111.

Cooper, P. J. M., Gregory, P. J., Tully, D., \& Harris, H. C. (1987). Improving water use efficiency of annual crops in the rainfed farming systems of West Asia and North Africa. Experimental Agriculture, 23, 113-158.

Deane, C., Ejeta, G., Rabbinge, R., \& Sayer, T. (2011). Science for global development: Mobilizing global partnerships. Crop Science, 50, 1-7.

Eley, R., Ibrahim, H., Hambly, H., Demeke, M., \& Smalley, M. (2003). The ILRI Graduate Fellows Program: A case study of impact. Education \& Training, 45, 162-174. 
El-Fadel, M., El Sayegh, Y., El-Fadel, K., \& Khorbally, D. (2003). The Nile River basin: A case study in surface water conflict resolution. Journal of Natural Resources \& Life Sciences Education, 32, 107-117.

Foxon, M. (1989). Evaluation of training and development programs: a review of the literature. Australian Journal of EducationalTechnology, 5, 89-104.

Hanson, R. G., Minor, H. C., Friere, J. R. J., \& Lehman, P. S. (1977). A simple method to identify research priorities when initiating research systems in developing countries. Journal of Agronomic Education, 6, 47-50.

ICARDA. (2007). Improving livelihoods in dry areas. Strategic plan (2007-2016). The International Center for Agricultural Research in the Dry Areas (ICARDA), Aleppo, Syria.

ICARDA. (2009). Food scarcity/poverty alleviation in arid agriculture: Baluchistan. GCP/PAK/095/USA Pilot Project Phase. The International Center for Agricultural Research in the Dry Areas (ICARDA), Aleppo, Syria.

ICARDA. (2010). The report of study team for third -country training program in the International Center for Agricultural Research in the Dry Areas (ICARDA) for crop improvement and seed technology (2004-2008). Japan International Cooperation Agency. International Center for Agricultural Research in the Dry Areas (ICARDA), Aleppo, Syria.

Kassam, A. H. (1981). Climate, soil and land resources in North Africa and West Asia. Plant \& Soil, 58, 1-29.

Kirkwood, J. I., Brams, E., \& Chang. Y. P. (1973). Worldwide rural poverty: an agronomist concern. Journal of Agronomic Education, 2, 59-64.

Kirkpatrick, D. (1983). Four steps to measuring training effectiveness. Personnel Administration, 28, 19-25.

Mason, S. C., Larry, S. R., \& Blue, E. N. (1987). Attitudes and conducting thesis research in a developing country. Journal of Agronomic Education, 16, 81-86.

Marsden, M. J. (1991). Evaluation: Towards a definition and statement of purpose. Australian Journal of Educational Technology, 7, 31-38.

Murdoch, J. T., Slammel, J. G., Erven, B. L., \& Kussow, W. R. (1972). Institutional organization for promoting rapid change in traditional agriculture. Journal of Agronomic Education, 1, 30-32.

Rhoades, R. E. (1984). Understanding small-scale farmers in developing countries: Socio-cultural perspectives on agronomic form trials. Journal of Agronomic Education, 13, 64-68.

Rohweder, D. A., Kussow, W. E. R., Ludwick, R. A. E., \& Drolsom, P. N. (1972). Research and graduate training as a basis for promoting rapid change in traditional agriculture. Journal of Agronomic Education, 1, 33-38.

Tindall, J. A., Robinson, L. R., Johnston, P. N., \& Jolley, V. D. (1984). An integrated small-scale agricultural model to aid developing countries. Journal of Agronomic Education, 13, 99-102.

Ryan, J., Garabet, S., Harmsen, K., \& Rashid, A. (1996). A soil and plant analysis manual adapted for West Asia and North Africa. The International Center for Agricultural Research in the Dry Areas (ICARDA), Aleppo, Syria.

Ryan, J., Masri, S., Garabet, S., Diekmann, J., \& Habib, H. (1997). Soils of ICARDA's agricultural experiment stations and sites: climate, classification, physical and chemical properties and land use. The International Center for Agricultural Research in the Dry Areas (ICARDA), Aleppo, Syria.

Ryan, J., Estephan, G., \& Rashid, A. (2001). Soil and plant analysis laboratory manual, $2^{\text {nd }}$ ed. The International Center for Agricultural Research in the Dry Areas (ICARDA), Aleppo, Syria.

Ryan, J., El-Mourid, M., Shroyer, J. P., \& El-Gharous, M. (2007). The Dryland Agriculture Applied Research Project in Morocco: A perspective 12 years after completion. Journal of Natural Resources \& Life Sciences Education, 36, 120-128.

Shroyer, M. G., Shroyer, J. P., \& Hicks, D. R. (1992). An extension methodology class: A component of an international development project. Journal of Natural Resources \& Life Sciences Education, 21, 175-177.

Swanson, B. E. (1975a). Evaluation of the CIMMYT wheat training program. Journal of Agronomic Education, 4, 85-89.

Swanson, B. E. (1975b). Evaluation of research training at IRRI. Journal of Agronomic Education, 4, 89-93.

Thijssen. M. H., Bishaw, Z., Beshir, A., \& de Boef, W. S. (200). Farmers, seeds and varieties: supporting 
informal seed supply in Ethiopia. Wageningen International, Netherlands.

Tillman, D., Cassman, K. B., Matson, P. A., Naylor, R., \& Polasky, S. (2002). Agricultural sustainability and intensive production practices. Nature, 418, 671-677.

Tripp, R., \& Anandajayasekeram, P. (1990). Building institutional capacity for on-farm research: Call system training courses. Journal of Agronomic Education, 19, 131-136.

Varma, S., \& Winslow, M. (2004). Healing Wounds: How the international centers of the CGIAR help rebuild agriculture in countries affected by conflicts and natural disasters. Consultative Group on International Agricultural Research (CGIAR), Washington, DC., USA.

Villareal, R. L., \& de Toro, E. (1993a). An assessment of a wheat improvement research training course for developing countries. Journal of Natural Resources \& Life Sciences Education, 22, 38-43.

Villareal, R. L., \& de Toro, E. (1993b). Competency evaluation of participants in a wheat improvement research training course. Journal of Natural Resources \& Life Sciences Education, 22, 44-48.

Van Schoonhoven, A. (1991). We two are a multitude. Journal of Agronomic Education, 20, 15-18. 